\title{
Contribuição na Avaliação Quali-quantitativa do Desempenho em Curso de Graduação
}

\author{
Ighor O. M. Rimes \\ Universidade do Estado do Rio de Janeiro- Instituto de Matemática e Estatística \\ Ciências Computacionais \\ 20550-013,Rua São Francisco Xavier, 524, RJ \\ E-mail: ighorimes@hotmail.com \\ Regina Serrão Lanzilloti \\ Universidade do Estado do Rio de Janeiro- Instituto de Matemática e Estatística \\ Ciências Computacionais \\ 20550-013,Rua São Francisco Xavier , 524, RJ \\ E-mail: reginalanzilloti@terra.com.br
}

\begin{abstract}
RESUMO
Há um interesse crescente em se saber como se desenvolve o avaliar dos alunos, embora muitos reconheçam que apenas provas não sejam suficientes. Realizam-se novas perspectivas para tentar compreender se o aluno obteve conteúdo suficiente para prosseguir [4] e a contribuição para o tema teve um grande fortalecimento no modelo avaliativo qualitativo [5]. De acordo com Haydt [1], avaliar é atribuir um julgamento com base em uma escala qualiquantitativa tendo critérios previamente estabelecidos, proposta que se acredita aceitável pela comunidade acadêmica, principalmente nas áreas humanas. Será que não se poderia criar um modelo diferenciado no avaliar o aprendizado sobre essa perspectiva?

As respostas poderiam estar embasadas na Lógica Fuzzy (LF) [2], modelagem que propicia um método mais justo de avaliação para alunos que venham a ter dificuldade, sobretudo na área tecnológica, embora mostre assiduidade tanto nas aulas quanto na monitoria. Este artigo apresenta resultados da disciplina Estatística em um curso de Geografia.

A LF é uma opção a modelar a avaliação com mais liberdade neste tipo de processo pedagógico, pois mapeia subjetividade, ambiguidade, incerteza e imprecisão. Esta proposta objetiva trabalhar com a LF sob o princípio de extensão para obter os valores de pertinência sob o enfoque interativo da Análise de Componentes Principais (ACP) [3]. As quatro variáveis de entrada do sistema, expressos em valores padronizados corresponderam a primeira prova, trabalho em equipe, segunda prova e a frequência. A ACP facilitou obter as pertinências da Lógica Fuzzy, pois reduziu a dimensão de quatro para duas componentes. O julgamento dos trabalhos dos alunos é realizado tanto pelo professor quanto pelo monitor, sendo que os comentários são contribuições que objetivam corrigir falhas sem melindrar os expositores. Esta forma de julgar torna-se um agente facilitador na interação professor, monitoria e discente. A aplicação da ACP mostrou que duas componentes já expressavam 83,67\% da variabilidade deste sistema avaliativo. No fator 1 as variáveis que mais contribuíram foram as nota 1 e nota 2 enquanto no fator 2 foi o trabalho e a presença. Os valores obtidos para estas componentes permitiram obter os percentis da Curva Normal Padrão (CNP) que integraram a Máquina de Inferência Fuzzy (MIF). Nesta máquina, obtiveram-se seis regras. Exemplificando, se um aluno obteve rendimento até o percentil 50 para as duas componentes, julga-se que deverá ser reprovado. As demais regras se tornam autoexplicativas na MIF.
\end{abstract}


Máquina de Inferência Fuzzy

\begin{tabular}{|l|l|l|l|l|}
\hline \multicolumn{2}{|c|}{ Antecedentes } & \multicolumn{3}{c|}{ Componente1 } \\
\cline { 3 - 5 } & Até P50 & Entre P50 e P75 & Acima P75 \\
\hline Componente 2 & Até P50 & Reprovado: R & $\begin{array}{l}\text { Tendência à } \\
\text { recuperação: TR }\end{array}$ & $\begin{array}{l}\text { Forte tendência à } \\
\text { recuperação:FTR }\end{array}$ \\
\cline { 2 - 5 } & Acima de P50 & $\begin{array}{l}\text { Recuperação } \\
\text { Improvável: RI }\end{array}$ & Aprovado: A & $\begin{array}{l}\text { Aprovado com } \\
\text { distinção: AD }\end{array}$ \\
\hline
\end{tabular}

As pertinências obtidas para os fatores corresponderam aos percentis da CNP e a pertinência de avaliação de cada aluno foi obtida pelo valor máximo dentre estas pertinências.

\section{Resultados da MIF}

\begin{tabular}{c|c|c|c|c}
\hline & \multicolumn{2}{|c|}{$\begin{array}{c}\text { Pertinências } \\
\text { (Percentis N(0,1)) }\end{array}$} & \multirow{2}{*}{$\begin{array}{c}\text { Pertinência de avaliação } \\
\text { (Máx Pert. F1 F2) }\end{array}$} & Consequente \\
\cline { 1 - 1 } Aluno & F1 & F2 & 0,93 & AD \\
\hline 1 & 0,91 & 0,93 & 0,19 & R \\
\hline 2 & 0,00 & 0,19 & 0,83 & FTR \\
\hline 3 & 0,44 & 0,83 & 0,68 & TR \\
\hline 4 & 0,68 & 0,35 & 0,68 & RI \\
\hline 5 & 0,09 & 0,68 & 0,93 & FTR \\
\hline 6 & 0,93 & 0,37 & 0,73 & RI \\
\hline 7 & 0,03 & 0,73 & 0,86 & FTR \\
\hline 8 & 0,86 & 0,02 & 0,95 & AD \\
\hline 9 & 0,95 & 0,56 & 0,58 & A \\
\hline 10 & 0,58 & 0,51 & &
\end{tabular}

O método proposto, de julgamento coerente, mostrou que $10 \%$ seriam reprovados, $30 \%$ aprovados e $60 \%$ recuperáveis, embora não se incluiu a prova de reposição e final.

Palavras-chave: Avaliação quali-quantitativa, Lógica Fuzzy, Análise de Componentes Principais.

\section{Referências}

[1] Haydt, R. C., "Avaliação do processo ensino-aprendizagem", São Paulo, Ática, 2002.

[2] Kosko, B., "Nebuloso Engineering". 1ed.,New Jersey, Prentice Hall Upper Saddle River, 1997.

[3] Morrison, D.F., "Multivariate Statistical Methods".2ed.Singapore, McGraw-Hill International Editions, 1988.

[4] Rosales, C., "Avaliar é refletir sobre o ensino",Rio Tinto: ASA, 1992.

[5] Saul, A.M., "Considerações a respeito do conceito de Currículo", Seminários Tendências e Prioridades de Currículo na Realidade Brasileira. Educ-anais, São Paulo, 1985. 